\title{
Use of $\mathrm{SF}_{6}$ to estimate anthropogenic $\mathrm{CO}_{2}$ in the upper ocean
}

\author{
Toste Tanhua, ${ }^{1}$ Darryn W. Waugh, ${ }^{2}$ and Douglas W. R. Wallace ${ }^{1}$ \\ Received 25 June 2007; revised 11 October 2007; accepted 31 December 2007; published 29 April 2008.
}

[1] The highest concentrations of anthropogenic carbon $\left(C_{a n t}\right)$ are found in the upper layers of the world ocean. However, this is where seasonal variability of inorganic carbon and related parameters due to thermal and biological effects complicates use of back-calculation approaches for $C_{a n t}$. Tracer based approaches to $C_{a n t}$ estimation are unaffected by biological variability and have found wide application. However, slow-down, even reversal, of the atmospheric growth of chlorofluorocarbons (CFCs) restricts use of these tracers for $C_{a n t}$ estimation for waters ventilated since the mid 1990s. Here we apply $\mathrm{SF}_{6}$, a tracer that continues to increase in the atmosphere, as a basis for the $C_{\text {ant }}$ estimation, using samples collected in the midlatitude North Atlantic in 2004. $C_{a n t}$ estimates derived from water mass transit time distributions (TTDs) calculated with $\mathrm{SF}_{6}$ are compared to those based on $\mathrm{CFC}-12$. For recently ventilated waters (pCFC-12 $>\sim 450 \mathrm{ppt}$ ), the uncertainty of $\mathrm{SF}_{6}$ based estimates of $C_{\text {ant }}$ is $\sim 6 \mu \mathrm{mol} \mathrm{kg}{ }^{-1}$ less than that of CFC-12 based estimates. CFC-12 based estimates remain more reliable for older (deeper) water masses, as a result of the longer input history and more readily detectable concentrations of $\mathrm{CFC}-12$. Historical data suggest that the near-surface saturation of CFC-12 has increased over time, in inverse proportion to its atmospheric growth rate. Use of a time-dependent saturation of CFC-12 in TTD calculations appears to provide more reliable estimation of $C_{a n t}$.

Citation: Tanhua, T., D. W. Waugh, and D. W. R. Wallace (2008), Use of $\mathrm{SF}_{6}$ to estimate anthropogenic $\mathrm{CO}_{2}$ in the upper ocean, J. Geophys. Res., 113, C04037, doi:10.1029/2007JC004416.

\section{Introduction}

[2] The World Ocean contains approximately 60 times as much inorganic carbon as the atmosphere, and the anthropogenic perturbation of oceanic dissolved inorganic carbon (DIC) in relation to pre-industrial levels range from approximately $3 \%$ (surface waters) to $0 \%$ (poorly ventilated deep water). Detection of this small anthropogenic change in DIC against a large and variable natural background represents a formidable analytical and conceptual challenge. A number of inference methods to estimate the oceanic $C_{a n t}$ concentration from field data have been developed; including socalled "pre-formed" approaches based on measurements of hydrochemical data such as inorganic carbon, alkalinity, nutrients and oxygen [e.g., Brewer, 1978; Chen and Millero, 1979; Gruber et al., 1996; Touratier and Goyet, 2004; Friis et al., 2005] or, alternatively, tracer-based approaches [e.g., Thomas and Ittekkot, 2001; Hall et al., 2002; Waugh et al., 2004]. These different approaches to estimate $C_{a n t}$ have various advantages and weaknesses [e.g., Wallace, 2001; Lo Monaco et al., 2005; Matsumoto and Gruber, 2005; Tanhua et al., 2007; Vázquez-Rodríguez et al., 2008]. Determination of $C_{a n t}$ in recently ventilated waters is particularly important

\footnotetext{
${ }^{1}$ Leibniz-Institut für Meereswissenschaften, Marine Biogeochemie, Kiel, Germany.

${ }^{2}$ Department of Earth and Planetary Sciences, Johns Hopkins University, Baltimore, Maryland, USA.
}

Copyright 2008 by the American Geophysical Union. 0148-0227/08/2007JC004416\$09.00 as this is where the highest concentrations of $C_{a n t}$ are found. However, it is in the upper water column that the seasonal variability of carbon related hydrochemical parameters arising from thermal and biological effects is the largest.

[3] Several $C_{\text {ant }}$ inference methods involve the use of transient tracer data, either to estimate the air-sea disequilibrium for carbon measurement based methods (e.g., the $\Delta C^{*}$ method of Gruber et al. [1996]) or as a basis for transfer functions between transient tracers and $C_{a n t}$. The most commonly used transient tracers for $C_{\text {ant }}$ inference are chlorofluorocarbons (CFCs; CFC-11 or CFC-12). However, the determination of $C_{a n t}$ using $\mathrm{CFCs}$ is problematic, especially for recently ventilated waters surveyed after the late 1990s, because the atmospheric concentrations of the $\mathrm{CFCs}$ are no longer increasing. The atmospheric concentration of CFC-11 has declined and that of CFC-12 has remained nearly constant since the late 1990s (Figure 1). The decrease in the atmospheric growth rate of CFC-12 is in sharp contrast to the rapidly increasing atmospheric concentration of $\mathrm{CO}_{2}$ (Figure 1, right hand panels) and limits the usefulness of CFC-12 as a proxy for $C_{\text {ant }}$. In contrast, the atmospheric concentration of another tracer, $\mathrm{SF}_{6}$, increases (Figure 1), and an increasing number of ocean measurements of $\mathrm{SF}_{6}$ are becoming available [i.e., Law and Watson, 2001; Watanabe et al., 2003; Vollmer and Weiss, 2002; Tanhua et al., 2004, 2005; Bullister et al., 2006]. This raises the possibility of using $\mathrm{SF}_{6}$ measurements as a proxy for $C_{a n t}$ for recently ventilated waters. The short atmospheric history 
Atmospheric $\mathrm{SF}_{6}$ and $\mathrm{CFC}-12$

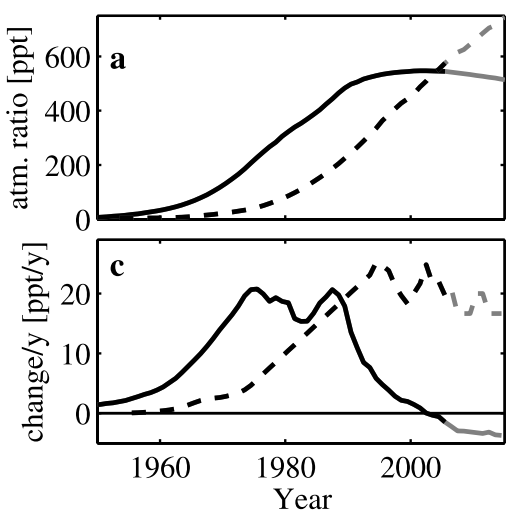

Atmospheric $\mathrm{CO}_{2}$

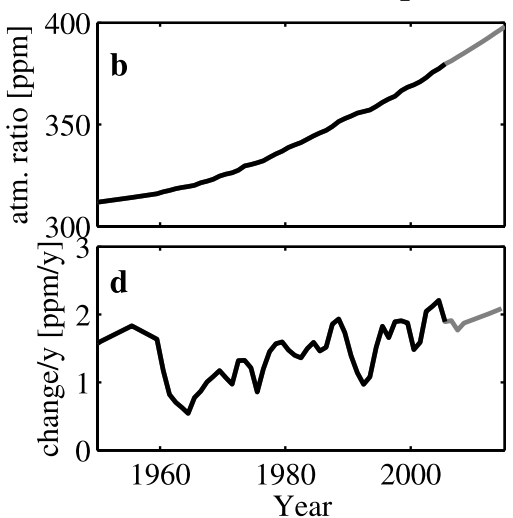

Figure 1. Comparison of atmospheric histories and increase rates of CFC-12, $\mathrm{SF}_{6}$ and $\mathrm{CO}_{2}$. Panel $\mathrm{A}$; the atmospheric mixing ratio of CFC-12 (solid lines) and $\mathrm{SF}_{6} * 100$ (dashed line). Panel C; the growth rate of the two tracers in the atmosphere $\left(\mathrm{SF}_{6} * 100\right)$, the trends are smoothed through a 3-year running mean filter. The atmospheric histories for CFC-12 are from Walker et al. [2000] updated from http:// gaslab.ucsd.edu/pub/cfchist; for $\mathrm{SF}_{6}$ from Maiss and Brenninkmeijer [1998] updated and normalized to data from NOAA/ESRL Global Monitoring Division http://www.cmdl.noaa.gov/infodata/ftpdata.html. Panels $\mathrm{B}$ and $\mathrm{D}$ shows the atmospheric history and growth rate $\mathrm{CO}_{2}$ (from the Mauna Loa and Law Dome records). The projections for the future (i.e., after year 2006) concentrations and growth rates for CFC-12, $\mathrm{SF}_{6}$ and $\mathrm{CO}_{2}$ used in this study are included in the figures as gray lines.

of $\mathrm{SF}_{6}$ on the other hand makes $\mathrm{SF}_{6}$ less suitable as a proxy for $C_{\text {ant }}$ for "older" waters.

[4] In this paper we evaluate the relative magnitudes and sources of uncertainty that influence $C_{a n t}$ estimation using CFC-12 and $\mathrm{SF}_{6}$. Specifically, we compare estimates of $C_{a n t}$ using the transit time distribution (TTD) approach [Hall et al., 2002] based on measurements of $\mathrm{CFC}-12$ and $\mathrm{SF}_{6}$, and we also compare those measurements with independent estimates calculated with the recently developed eMLR method [Friis et al., 2005; Tanhua et al., 2007].

\section{Methods}

\subsection{Tracer Measurements}

[5] The data presented here was collected from the midlatitude North Atlantic during the spring of 2004 [Tanhua et al., 2006]. The cruise track of Meteor cruise 60 Leg 5 was from Martinique to Lisbon, with a northernmost station at $42^{\circ} \mathrm{N}$, and the cruise therefore included sampling of both the subtropical and subpolar gyres, as well as the western and eastern basins (Figure 2). The data are archived at the Carbon Dioxide Information Analysis Center, Oak Ridge National Laboratory, USA, (http://cdiac.esd.ornl.gov/). The anthropogenic carbon content from this data set has been estimated using an empirical approach $\left(C_{\text {ant }}^{e M L R}\right)$, using measurements made 23 years earlier. The resulting $C_{a n t}$ estimates were compared to $C_{\text {ant }}$ estimates calculated from TTDs based on CFC-12 data [see Tanhua et al., 2007]. The latter study considered the full water column, but had a special emphasis on the problems of $C_{a n t}$ detection in deep and intermediate water masses, in this paper we focus on the upper water column only $(0-2000 \mathrm{~m})$.

[6] The determination of $\mathrm{SF}_{6}$ was performed by purgeand-trap gas chromatography with electron capture detection [see Tanhua et al., 2005]. The analytical precision was $1.5 \%$, the detection limit was estimated to be $0.05 \mathrm{fmol} \mathrm{kg}$ ( $\sim 0.15 \mathrm{ppt}$ ). A sampling blank (determined from analyses of deep water samples in the Eastern Basin) of the same magnitude has been subtracted from the data. The $\mathrm{SF}_{6}$ data were calibrated against an air standard prepared at CMDL, Boulder, CO, and are reported on to the GMD2000 scale (http://www.cmdl.noaa.gov/hats/standard/SF6_scale.htm).

[7] The CFC measurements were made on an analytical system similar to that described by Bullister and Weiss [1988] and are reported on the SIO98 scale [Prinn et al., $2000]$. The analytical precision was $0.7 \%$ for CFC-12, and a sampling blank of $0.007 \mathrm{pmol} \mathrm{kg}^{-1}$ (determined as the median value of 18 deep water samples in the eastern basin) has been subtracted from the data.

[8] To eliminate the effects of variable temperature and salinity on the tracer solubility, we report tracer concentrations as the equivalent dry air mole fraction for a gas phase in equilibrium with the seawater sample, $\mathrm{pCFC}$ or $\mathrm{pSF}_{6}$, i.e.:

$$
p C F C=\frac{C_{C F C}}{F(\theta, S)} .
$$

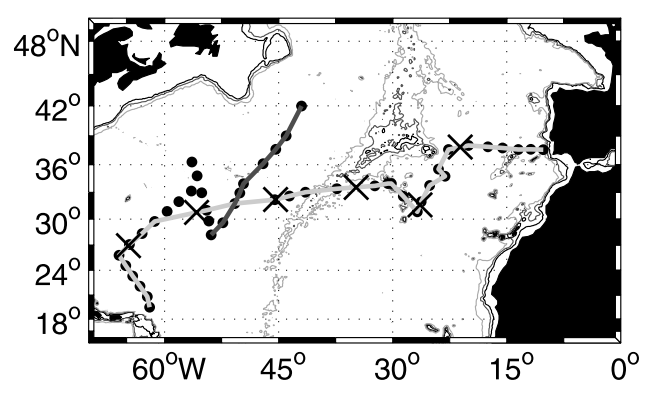

Figure 2. Map of the stations occupied during the M60/5 cruise in 2004 (black dots). The light gray line marks the position of the sections shown in Figure 6, where crosses marks every $1000 \mathrm{~km}$ distance. The dark gray line marks the sections shown in Figure 7. 
[9] The salinity and temperature dependent solubility of the tracers, $F(\theta, \mathrm{S})$, are calculated from their respective solubilities [Bullister et al., 2002; Warner and Weiss, 1985], and we have assumed an atmospheric pressure of 1 atmosphere. In this way, tracer concentrations can be compared directly to their time-varying atmospheric histories [Maiss and Brenninkmeijer, 1998; Walker et al., 2000] so that "tracer ages" and TTDs of the samples can be determined. We will use the term "tracer age" $(\tau)$ for the age derived by simple matching of the tracer concentration (in ppt) to the atmospheric history of the tracer.

\subsection{The TTD Method to Determine $\boldsymbol{C}_{\text {ant }}$}

[10] In principle, the concentration, $c$, of a passive tracer in the ocean can be determined at any point, $r$, and time, $t$, with knowledge of the transit time distribution, TTD, and the input function of the tracer at the sea-surface, $c_{0}(t)$, according to

$$
c(r, t)=\int_{0}^{\infty} c_{0}\left(t-t^{\prime}\right) G\left(r, t^{\prime}\right) d t^{\prime}
$$

where $\mathrm{G}(\mathrm{r}, \mathrm{t})$ is the TTD. To use this equation to calculate $C_{a n t}$ it is necessary to know the TTD at each interior ocean location as well as the surface history of $C_{a n t}$. Several different approaches have been used to estimate TTDs. For example, Thomas et al. [2001] used TTDs obtained from an ocean circulation model, whereas Hall et al. [2002, 2004] and Waugh et al. [2004, 2006] estimated TTDs from observations of the concentrations of CFCs and other transient tracers.

[11] Here we use the implementation of Waugh et al. [2004, 2006], and we refer the reader to these papers for more details. In this implementation, the TTD at each interior location is assumed to be an inverse Gaussian function [Waugh et al., 2003], with the mean age $(\Gamma)$ being equal to the width of the TTD $(\Delta)$. Waugh et al. [2004] demonstrated that TTDs with $\Delta=\Gamma$ is consistent with simultaneous observations of several different transient tracers. With the assumption of a fixed relation between $\Gamma$ and $\Delta$, the TTD can be defined by the observation of a single transient tracer (e.g., CFC-12 or $\mathrm{SF}_{6}$ ). The method thus allows for the effects of ocean mixing $(\Delta)$ to be considered in establishing the transfer function between the measured tracer concentration and $C_{\text {ant }}$.

[12] The atmospheric history of $\mathrm{CO}_{2}$ is well documented, and by treating concentrations in excess of $280 \mathrm{ppm}$ as the anthropogenic perturbation, $C_{a n t}$ can be viewed as a passive transient tracer. The transfer of inorganic carbon from the atmosphere to the ocean is dependent on the buffer-capacity of seawater at the time when the water was in contact with the atmosphere. By using the empirical relations between surface salinity and alkalinity [e.g., Brewer et al., 1986] this can be determined from inorganic carbon chemistry and a knowledge of salinity and temperature alone, and hence the oceanic $C_{a n t}$ input function for each water sample can be determined. The TTD of each sample is determined from measurements of transient tracers, and the $C_{a n t}$ can then be estimated using the above equation. The TTD method as used here implicitly assumes time-invariable air-sea equi- librium of $\mathrm{CO}_{2}$, and any temporal changes in the $\mathrm{CO}_{2}$ saturation state will cause systematic biases in the method.

\section{Uncertainties in the TTD Method of $C_{a n t}$ Estimation}

\subsection{Sources of Uncertainty and Error}

[13] In order to calculate the TTD of a water-sample, the measured tracer concentration has to be compared with the atmospheric history of the tracer. Errors can arise due to: analytical errors in the tracer measurements; uncertainties in the atmospheric history; uncertainties in the $\Delta / \Gamma$ ratio; and uncertainties in the initial degree of saturation of the tracers. We will discuss each of these error sources below.

[14] The uncertainties in the historical atmospheric mixing ratios of the transient tracers CFC-11, CFC-12, CFC-113 and $\mathrm{CCl}_{4}$, as estimated from instrumental records as well as (for earlier periods) industrial production and emission data, are discussed and documented by Walker et al. [2000]. For the CFCs these uncertainties are less than $4 \%$ for most of the period before reliable atmospheric measurements started, and are considerably less since then. The error in the instrumental record for $\mathrm{SF}_{6}$ atmospheric concentration is also relatively small, $(\sim 1 \%)$ (http:// www.cmdl.noaa.gov/infodata/ftpdata.html), but again, uncertainties of atmospheric levels are higher for periods where estimates need to reconstructed based on reported global sales, estimated emissions, atmospheric lifetimes, etc.

[15] The concentration of tracers in seawater can be determined to high accuracy and precision. Realistic numbers for combined calibration and analytical uncertainties are about $2 \%$ for $\mathrm{CFC}-12$ and $4 \%$ for $\mathrm{SF}_{6}$ [e.g., Bullister et al., 2006; Tanhua et al., 2004]. For samples with low concentrations, the relative error is generally higher so that the error is better represented by an absolute concentration.

[16] A further potential source for bias in $\mathrm{SF}_{6}$ measurements is contamination from any deliberate $\mathrm{SF}_{6}$ injections to the interior of the oceans. These have been conducted since the mid 1980s, and the tracer quantity and position of the releases are well documented [e.g., Watson and Ledwell, 2000; Tanhua et al., 2004; Schmitt et al., 2005]. Obviously, care should be taken to avoid influence of any deliberately released $\mathrm{SF}_{6}$ on the $C_{a n t}$ calculations. With this problem in mind, a community agreement was reached at the AGU Ocean Science Meeting in 2006 to avoid future use of $\mathrm{SF}_{6}$ in large-scale sub-surface ocean releases.

[17] Most often the surface tracer concentration is not fully in equilibrium with the atmosphere, particularly during winter time convection. Hence further uncertainty arises from the need to assume or estimate a degree of air-water equilibration (saturation) for the tracer at the time of water mass formation. This uncertainty in the assumed saturation is usually larger than the analytical error. It is known that the depth of the seasonal mixed layer as well as the rate of atmospheric increase influence the surface saturation of the tracers [e.g., Haine and Richards, 1995]. For instance, water masses that are formed during very deep convection have been reported to have CFC saturations as low as $60 \%$ [Wallace and Lazier, 1988]. Similarly, DeGrandpre et al. [2006] found under-saturated conditions in the Labrador Sea through the whole year with respect to $\mathrm{CO}_{2}$. Comparing 


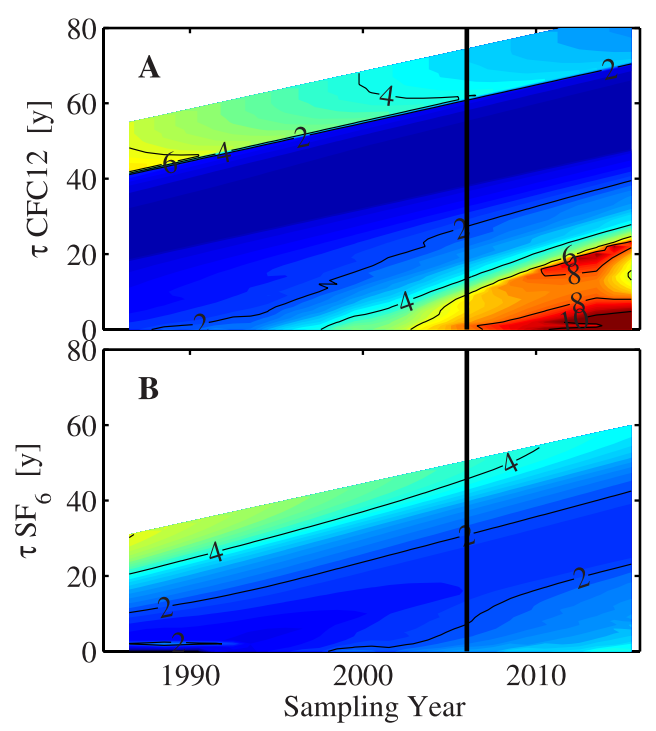

Figure 3. Errors in $C_{\text {ant }}$ calculations using the TTD method (in $\mu \mathrm{mol} \mathrm{kg} \mathrm{kg}^{-1}$ ). For these calculations, we have assumed $6 \%$ error in correctly assuming the saturation of the tracer and an analytical error of $4 \%$ or $0.1 \mathrm{ppt}$ for $\mathrm{SF}_{6}$ and $2 \%$ or 5 ppt for CFC-12, whichever of these two errors are the largest. These errors are color-contoured as a function of sampling year and tracer age $(\tau)$ for the respective tracer. Panel A; calculated with CFC-12 data; and Panel $\mathrm{B}$ with $\mathrm{SF}_{6}$ data. The areas to the right of the black line are future projections of the error assuming a trend for the tracers as in Figure 1, as well as exponentially increasing $C_{\text {ant }}$ concentration.

CFC measurements from the ocean interior with data simulated in an advection-diffusion model, Mecking et al. [2004] estimated initial saturations of CFC-12 ranging from $80-100 \%$, with the initial saturation being correlated with density. Similarly, by comparing the saturation of all surface water samples from a cruise in the Southern Ocean, Tanhua et al. [2004] found uncertainties in saturation of $\sim 5 \%$. The combined error in determination of the tracer equilibrium concentration can thus be in the order of $10 \%$, or larger for lower concentration samples. These errors will lead to errors in estimated $C_{\text {ant }}$, particularly for time periods when the tracer concentration in the atmosphere has increased slowly (see below).

[18] The TTD-method is dependent on an assumed shape for the TTD. In the case of the inverse Gaussian distribution that has been assumed here, the relation between the mean age and the width of the TTD, i.e., the $\Delta / \Gamma$ ratio, is critical. The effect of varying this ratio on $C_{a n t}$ estimation has been demonstrated by Waugh et al. [2004], Figure 7. Although there are large differences in $C_{a n t}$ for $\Delta / \Gamma$ ratio that vary from 0 to 1 (i.e., between a "no mixing" case and "more realistic" mixing), the difference between, for instance, ratios of 1.25 or 0.75 versus unity are relatively small (on the order of $1 \mu \mathrm{mol} \mathrm{kg}{ }^{-1}$ ).

[19] There are additional sources of uncertainty in the TTD approach to $C_{\text {ant }}$ estimation, including not accounting for possible anthropogenic effects on the biological or physical transport of carbon within the ocean interior, and the assumption of time-independent air-sea disequilibrium for $\mathrm{CO}_{2}$. Even though the saturation of $C_{\text {ant }}$ and CFC tracers have fundamentally different response to changes in temperature [Thomas and England, 2002], a general warming (or cooling) of the oceans will not directly influence $C_{a n t}$ estimates using the TTD method since temperature is accounted for. A potentially significant error could be introduced by changes in the air-sea equilibrium of $\mathrm{CO}_{2}$ and tracers (a method allowing for time-variant air-sea disequilibrium of $\mathrm{CO}_{2}$ is demonstrated by Hall et al. [2004]). These uncertainties apply equally to the $C_{a n t}$ estimates independent of the tracer (e.g., $\mathrm{SF}_{6}$ or $\mathrm{CFC}-12$ ) used to calculate the TTD, and are not discussed further here.

\subsection{Time and Age-Dependence of Uncertainties}

[20] Due to variability in historical atmospheric growth rates, the magnitude of errors associated with most of the sources of uncertainty listed above will differ depending on which tracer is used (e.g., $\mathrm{SF}_{6}$ or CFC-12). Errors will also vary with the "age" of the water mass, and the time of sampling. The uncertainties in $C_{\text {ant }}$ estimates for the two tracers are plotted as a function of tracer age and year of sampling in Figure 3. The plot is based on an assumed $6 \%$ uncertainty in the saturation of the tracer. The analytical uncertainties is assumed to be $4 \%$ or 0.1 ppt for $\mathrm{SF}_{6}$ and $2 \%$ or 5 ppt for CFC-12 (whichever of the absolute or percentage error is the largest).

[21] For this analysis we have also included uncertainty in the atmospheric history as given by Walker et al. [2000] for $\mathrm{CFC}-12$, and an assumed error for $\mathrm{SF}_{6}$ of $0.005 \mathrm{ppt}$. We applied projections for the atmospheric concentrations of $\mathrm{CO}_{2}$ and the tracers as shown in Figure 1 in order to assess possibly future uncertainties.

[22] Figure 3, top panel, shows that errors in $C_{a n t}$ calculated from TTDs based on CFC-12 $\left(C_{\text {ant }}^{F 12}\right)$ are high for "young" samples that have been sampled recently (or will be sampled in the future). This is due to the reduced (or negative) atmospheric growth rate of CFC-12 since the mid 1990 s. There is also a band of larger errors for the "oldest" measurable tracer ages. These errors mainly arise from analytical uncertainty, in this case assumed to be $5 \mathrm{ppt}$ which corresponds to a blank of roughly $0.03 \mathrm{pmol} \mathrm{kg}^{-1}$. This may be a worst-case scenario.

[23] The situation for the error in $C_{a n t}$ calculated with TTDs based on $\mathrm{SF}_{6}\left(C_{\text {ant }}^{S F 6}\right)$ is different (Figure 3, lower panel), with relatively low errors for "younger" waters but with analytical errors being more significant for "older" samples due to lower concentrations and lower analytical precision for $\mathrm{SF}_{6}$ compared to $\mathrm{CFC}-12$. The reason for the absence of a band of high errors for old samples is due to the different way in which we have treated very low $\mathrm{SF}_{6}$ concentrations: for CFC-12 it is often assumed (also for our analysis) that zero $\mathrm{CFC}-12$ concentration equals zero $C_{\text {ant }}$, whereas for $\mathrm{SF}_{6}$ we assigned samples with zero $\mathrm{SF}_{6}$ concentration to "not available". The reason for the different treatment is the significantly different length of the atmospheric histories of the two tracers. However, since the anthropogenic emissions of $\mathrm{CO}_{2}$ started over 150 years before emissions of CFC-12, $C_{\text {ant }}$ can potentially be present also in CFC-12 samples below the detection limit. In fact, the surface ocean imprint of $C_{a n t}$ around 1940 (i.e., before 
Table 1. List of Cruises From the Preliminary Release of the CARINA Database That Have Been Used for Our Analysis of Historical Saturation of CFC-12, See http://cdiac.ornl.gov/oceans/CARINA/Carina_inv.html; Carbon Dioxide ${ }^{a}$

\begin{tabular}{lll}
\hline \multicolumn{1}{c}{ Expocode } & \multicolumn{1}{c}{ Chief Scientist } & \multicolumn{1}{c}{ CFC PI } \\
\hline 34AR19970805 & H. Gronvall \& J. Launiainen & T. Tanhua \\
74DI19970807 & A. F. Rios & D. Smythe-Wright \\
32EV19910529 & ? & ? \\
58GS20030922 & T. Johannessen & K.A. Olsson \& E. Jeansson \\
18HU19820228 & R. Clarke, JL Reid, J Swift & R. Weiss \& D. Wallace \\
18HU19920527 & J. Lazier & P. Jones \\
18HU19930617 & J. Lazier & P. Jones \\
18HU19931115 & A. Clarke & P. Jones \\
18HU19940524 & J. Lazier & P. Jones \\
18HU19941012 & A. Clarke & P. Jones \\
18HU19970509 & A. Clarke & P.Jones \& R. Gershey \\
58JH19911106 & J. Blindheim & J. Bullister \\
58JH19931107 & J. Blindheim \& F.Rey & J. Bullister \\
58JH19940723 & J. Blindheim & E. Fogelqvist \& T.Tanhua \\
58JH19941029 & J. Blindheim \& F. Rey & J. Bullister \\
58JH19951108 & F. Rey & J. Bullister \\
58JH19961030 & J. Blindheim \& F. Rey & J. Bullister \\
58JH19970425 & J. Blindheim \& F. Rey & J. Bullister \\
58JH19990616 & J. Blindheim \& F. Rey & J. Bullister \\
06MT19941012 & P. Koltermann \& J. Meincke & W. Roether \\
06MT19941115 & J. Meincke $~$ & W. Roether \& M. Rhein \\
06MT19970517 & W. Zenk \& T. Mueller & O. Plöhn \\
06MT19970707 & F. Schott & M. Rhein \\
06MT20040311 & D. Wallace & T. Tanhua \\
\hline
\end{tabular}

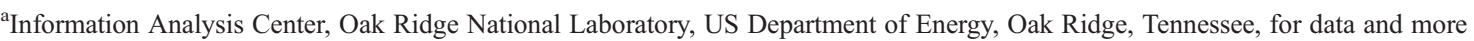
details. The year of sampling can be as characters $5-8$ in the expocode.

the use of CFCs) was in excess of $10 \mu \mathrm{mol} \mathrm{kg}{ }^{-1}$. However, applying the TTD method to contemporary CFC data with a detection limit of $0.005 \mathrm{pmol} \mathrm{kg}^{-1}$, this error will only be about $2 \mu \mathrm{mol} \mathrm{kg}{ }^{-1} C_{\text {ant }}$, due to the effects of mixing.

[24] The uncertainty in the atmospheric history is of second order importance in comparison to analytical errors for the low concentration range of both tracers. For the recently ventilated samples, the estimate is dependent more on atmospheric history as determined by instrumental measured records of $\mathrm{CFC}-12 / \mathrm{SF}_{6}$, and these are very accurate (see above).

\section{Results From the North Atlantic}

\subsection{Initial Saturation of the Tracers}

[25] We start our analysis with the uncertainty in $C_{a n t}$ associated with uncertainty in the initial surface saturation of the tracer. During the M60/5 cruise, the average surface saturation for CFC-12 was 100\% (standard deviation 3.8\%), whereas for $\mathrm{SF}_{6}$ it was only $88 \%$ (standard deviation $7.5 \%$ ). The difference is possibly associated with the difference in the contemporary atmospheric growth rates of the two tracers. To test this hypothesis we analyzed the mean saturation of CFC-12 for all the North Atlantic cruises in the GLODAP database [Key et al., 2004] as well as a preliminary version of the CARINA database (see Table 1 for details). Even though the data were collected from cruises from various regions of the North Atlantic (including the Nordic Seas and the Labrador Sea), and were sampled during various seasons, there is a tendency for CFC-12 to have been under-saturated during earlier cruises, and to be close to saturation for later cruises (Figure 4a). In fact, a 2 nd order polynomial fit to the data resembles the shape of the atmospheric concentration over time for
CFC-12 with a time-lag of $\sim 5$ years (Figure 1a). To test this we plotted the best fit of the CFC-12 saturation from Figure $4 \mathrm{a}$ versus the atmospheric growth rate of CFC-12 (Figure 1c) in Figure 4b.

[26] The apparent inverse correlation between atmospheric growth rate and surface saturation for CFC-12 is presumable typical for other $\mathrm{CFCs}$ and $\mathrm{SF}_{6}$ as well. Typical gasexchange velocities can equilibrate shallow surface mixed layers with the atmosphere on timescales of weeks to months. In comparison, atmospheric growth (e-folding) timescales for these compounds were never less than several years which implies that the rate of gas transfer into shallow mixed layers is not the reason for this inverse correlation. The correlation is more likely associated with temporal trends in subsurface vertical gradients of the tracers in the context of deep mixing and/or mixing with sub-surface water. Specifically, it implies that the subsurface gradients of CFC-12 have become less steep as its atmospheric growth rates has decreased. In a deep-mixing scenario, this implies less dilution of surface CFC-12 levels by sub-surface waters entrained during convection. In an upwelling scenario, the surface layer CFC-12 is diluted to a lesser extent by upwelled water.

[27] Figure 1 shows that the $\mathrm{SF}_{6}$ atmospheric growth rate has remained relatively constant over the last $\sim 20$ years whereas the CFC-12 growth rate has decreased steadily over the same time period; this implies that $\mathrm{SF}_{6}$ surface saturations are likely to have remained more constant than CFC12 saturations over the same period. We therefore calculated TTDs with $\mathrm{SF}_{6}$ data from $\mathrm{M} 60 / 5$ for a time-invariant surface saturation of $86 \%$. Note that this value is very similar to the best fit CFC-12 saturation around 1990 at a time when the CFC-12 atmospheric growth rate was similar to the presentday $\mathrm{SF}_{6}$ atmospheric growth rate. The TTDs based on $\mathrm{SF}_{6}$ 

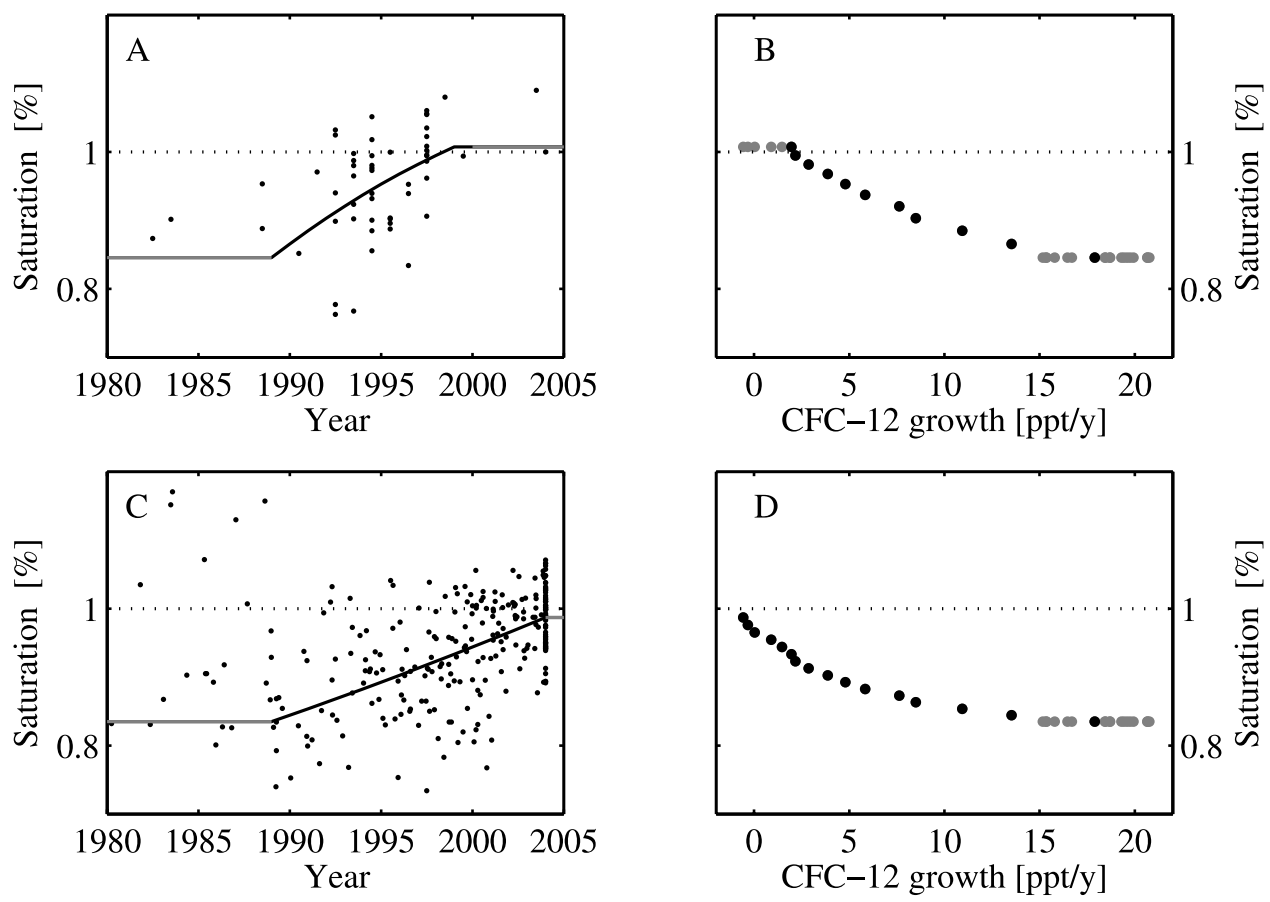

Figure 4. Panel A: The per cruise mean saturation of CFC-12 from each of the North Atlantic cruises in the GLODAP [Key et al., 2004] and a preliminary version of the CARINA (http://cdiac.ornl.gov/oceans/ CARINA/Carina_inv.html, Table 1) databases. The combined data set consists of 57 independent cruises with CFC-12 data to the North Atlantic. The black line is a 2nd order polynomial fit to the data between 1985 and 2000, constant saturation is assumed before and after these times (gray line). Panel B: The CFC-12 saturation as determined from the fit in panel A plotted versus the atmospheric annual growth rate of CFC-12 (Figure 1c) as black dots (gray dots for the time outside of the fit, where the saturation is set). Panel $\mathrm{C}$ : The $\mathrm{SF}_{6}$ ventilation year in each data point from the $\mathrm{M} 60 / 5$ cruise, assuming $86 \%$ saturation versus the saturation of $\mathrm{CFC}-12$ determined by the best fit with the $\mathrm{SF}_{6}$ mean ages. Panel D: The CFC-12 saturation as determined from the fit in panel $\mathrm{C}$ plotted versus the atmospheric annual growth rate of CFC-12 (Figure 1c) as black dots (gray dots for the time outside of the fit, where the saturation is set).

data were used to predict CFC-12 concentrations for the same water samples based on an assumption of time-invariant $100 \%$ initial saturation, and the predicted CFC-12 concentrations were compared to measured values. Figure $4 \mathrm{c}$ shows the corresponding ratios of measured/predicted CFC-12 versus the mean age of the water sample, and this ratio is also plotted versus the atmospheric growth rate in Figure $4 \mathrm{~d}$. If the $\mathrm{SF}_{6}$ based TTDs are accurate, then the measured/ predicted ratio of $\mathrm{CFC}-12$ is an indication of the initial surface saturation of CFC-12.

[28] These two lines of evidence, i.e., the historical CFC-12 data and the comparison of $\mathrm{SF}_{6}$ and $\mathrm{CFC}-12$ data from the M60/5 cruise, suggest that the surface saturation of these tracers are inversely correlated with the atmospheric growth rate. Time-dependent saturation of CFC-12 and CFC-11 has been observed in the Labrador Sea [Azetsu-Scott et al., 2003, 2005], where the variations in saturation were correlated to different convection regimes in the Labrador Sea. A similar time-dependence for the saturation of CFC-11 was found by Zhao et al. [2006, Figure 13] for the Labrador Sea from an ocean circulation model.

[29] Hence for the calculations below we have assumed a time-varying saturation of CFC-12 which follows the solid line shown in Figure $4 \mathrm{a}$, where the saturation for recent samples is set to $100 \%$ and for older samples to $86 \%$. There are too few data to constrain the surface saturation with growth rate further back in time. We also use a timeinvariant saturation of $86 \%$ for $\mathrm{SF}_{6}$ since this is close to the measured saturation during 2004 and because the contemporary atmospheric growth rate of $\mathrm{SF}_{6}$ is similar to that of CFC-12 during the 1970s and 1980s. The assumed constant saturation of $\mathrm{SF}_{6}$ regardless of tracer age, is necessary due to a lack of historic data and justified by the almost linear increase of $\mathrm{SF}_{6}$ since about 1990. The influence of other, potentially important, factors including temporal variation in the depth of convection is not considered. However, as we will see below, even such a simple treatment of time-variable saturation improves the agreement between $C_{\text {ant }}$ estimates calculated using CFC-12 and $\mathrm{SF}_{6}$.

\subsection{Distribution of Tracers and $\mathbf{C}_{\text {ant }}$}

[30] The TTD method as described above was used to estimate $C_{a n t}$ from $\mathrm{SF}_{6}$ and $\mathrm{CFC}-12$ measurements from the 2004 North Atlantic cruise M60/5. In the $C_{\text {ant }}$ calculations shown below we use $\Delta / \Gamma=1$ and the above-described treatment of initial saturations of the tracers. Inevitable some samples will be "supersaturated" (i.e., will have a 

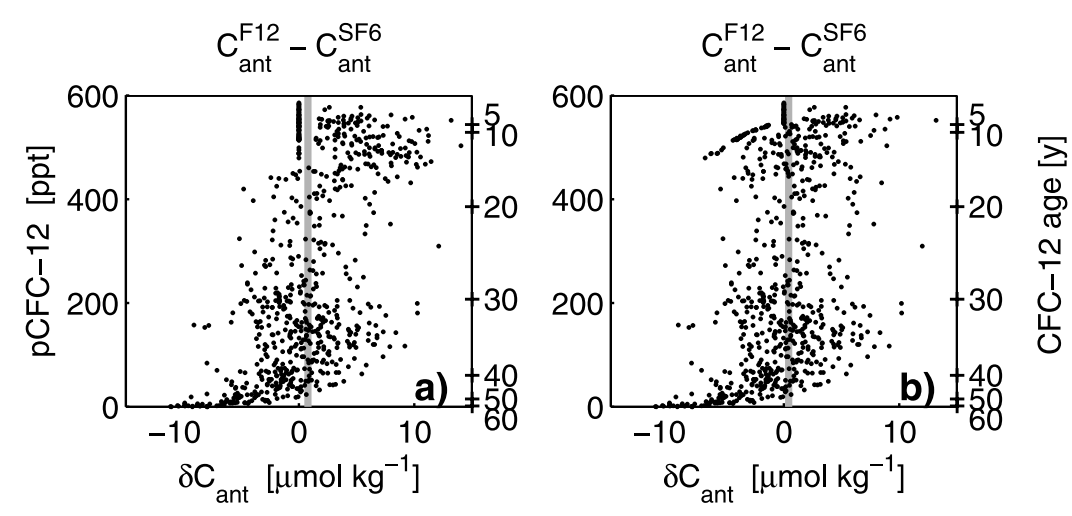

Figure 5. Difference in anthropogenic carbon content from the M60/5 cruise calculated using the TTD method, based either on $\mathrm{SF}_{6}$ or $\mathrm{CFC}-12$ measurements, plotted versus pCFC-12. The gray lines mark the mean difference in the range 100 to $450 \mathrm{ppt} C F C-12$. The right hand scale of the panels shows the CFC-12 tracer age $(\tau)$ corresponding to the pCFC-12 on the left hand scale. In panel A we have assumed a constant saturation of $86 \%$ for both tracers, whereas in panel B we have assumed a time-dependent saturation for CFC-12 (the line in Figure 4a), and $86 \%$ saturation for $\mathrm{SF}_{6}$.

saturation in excess of $86 \%$ for $\mathrm{SF}_{6}$, resulting in "negative ages"), primarily close to the surface. Samples with dry air mole fraction equivalent for the tracer that are in excess of contemporary values were therefore set to be "recent" (i.e., age $=0 \mathrm{y})$ and the $C_{a n t}$ concentration was calculated from the contemporary atmospheric $\mathrm{pCO}_{2}$ of 2004 .
[31] Figure 5 compares estimates of $C_{a n t}$ calculated from the $\mathrm{SF}_{6}\left(C_{a n t}^{S F 6}\right)$ and CFC-12 $\left(C_{a n t}^{F 12}\right)$ measurements. Panel (a) shows results calculated for the time-invariant saturation for both tracers of $86 \%$, whereas panel (b) presents results calculated with the time-dependent surface saturation of CFC-12. The difference between the $C_{a n t}^{F 12}$ and $C_{a n t}^{S F 6}$ tends to zero in the surface waters because our approach forces
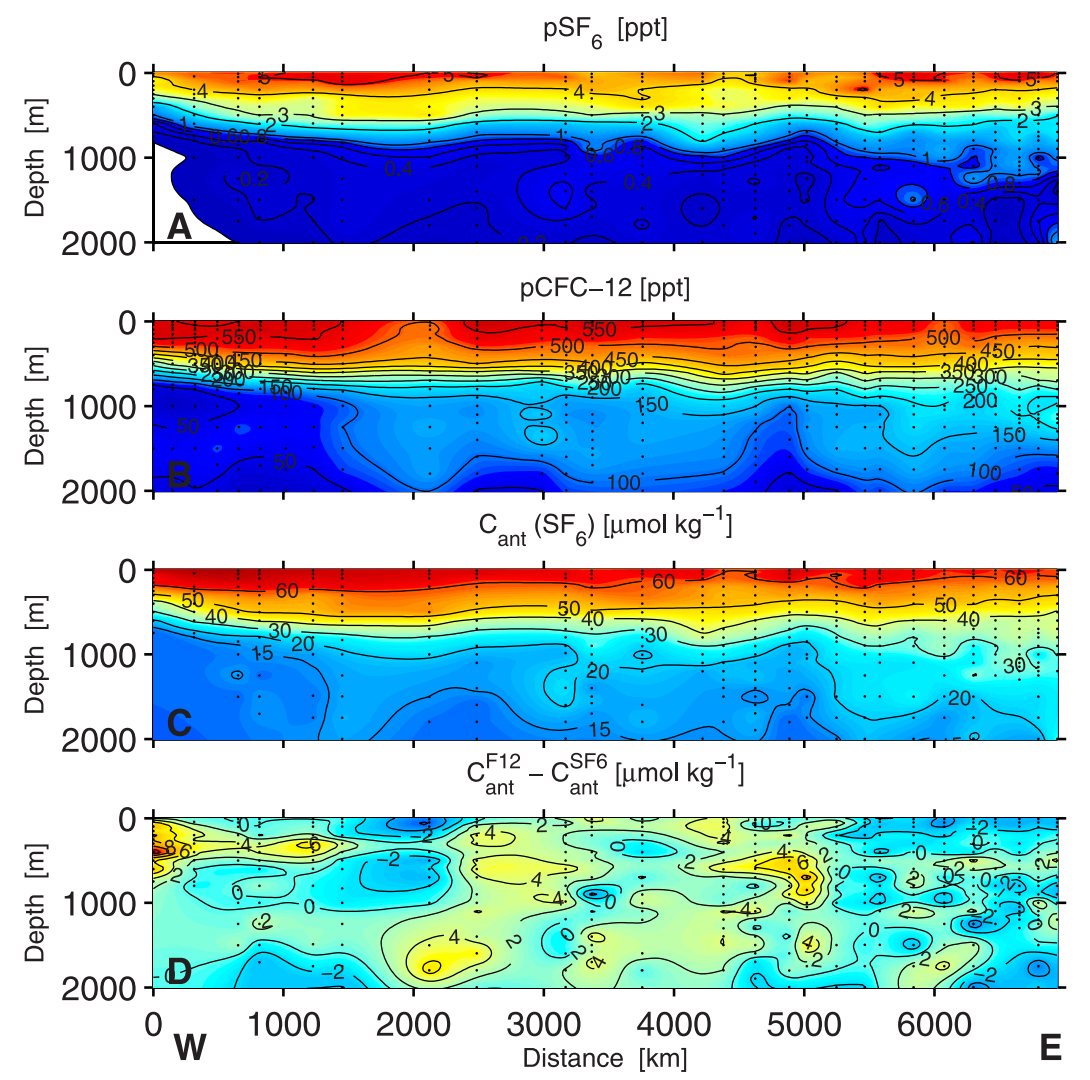

Figure 6. West-east sections of the top $2000 \mathrm{~m}$ depth across the midlatitude North Atlantic (Figure 2, light gray line). Panel $\mathrm{A}$ shows the measured $\mathrm{pSF}_{6}$ concentration [ppt]; Panel $\mathrm{B}$ the measured pCFC-12 concentration [ppt]; Panel C the $C_{a n t}^{S F 6}$ concentration $\left[\mu \mathrm{mol} \mathrm{kg}^{-1}\right]$; Panel D shows the difference $C_{a n t}^{F 12}-C_{a n t}^{S F 6}\left[\mu \mathrm{mol} \mathrm{kg}^{-1}\right]$. 

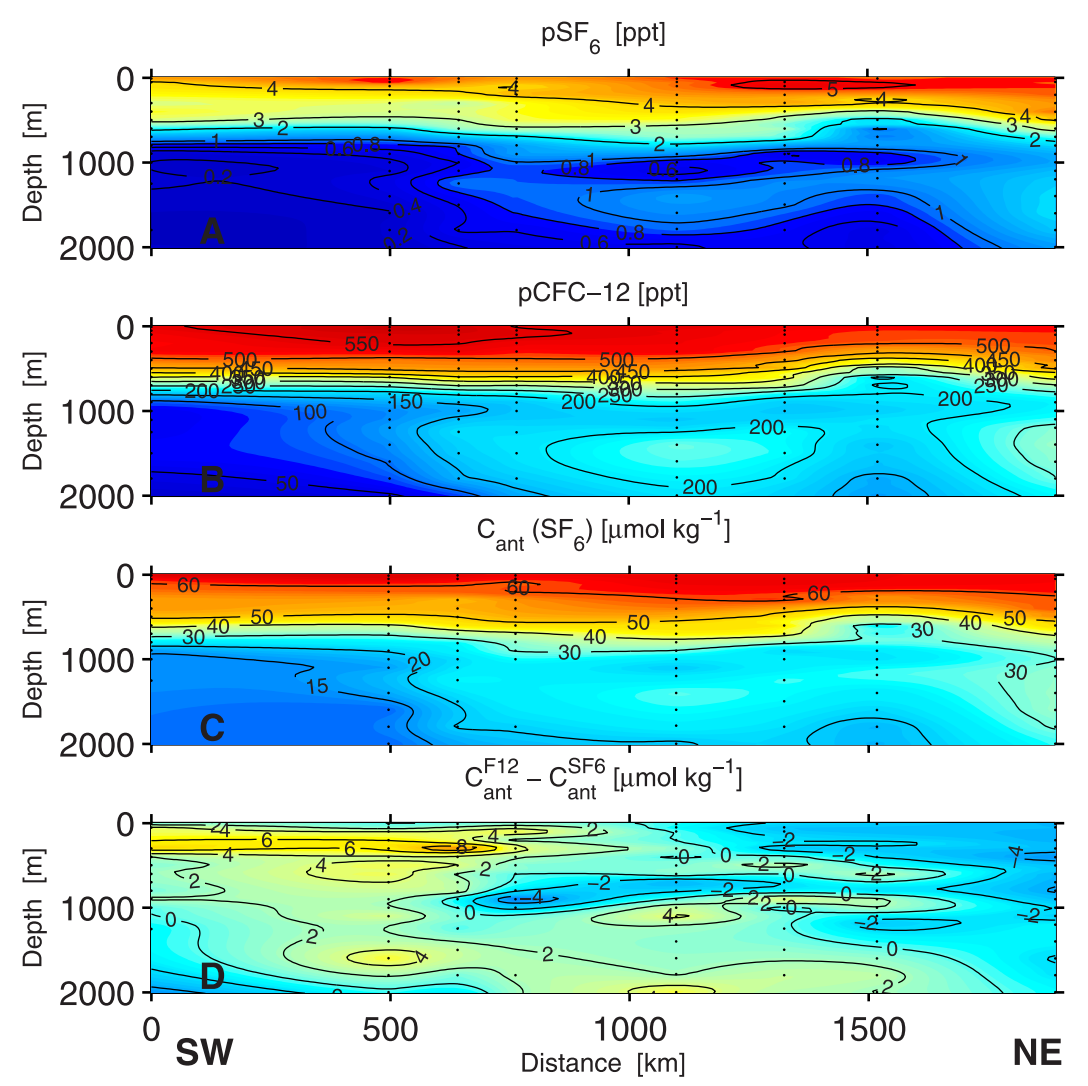

Figure 7. South-north sections of the top 2000 meters depth across the midlatitude North Atlantic (Figure 2, dark gray line). Panel A shows the measured $\mathrm{pSF}_{6}$ concentration [ppt]; Panel B the measured pCFC-12 concentration [ppt]; Panel C the $C_{a n t}^{S F 6}$ concentration $\left[\mu \mathrm{mol} \mathrm{kg}^{-1}\right]$; Panel D shows the difference $C_{\text {ant }}^{F 12}-C_{\text {ant }}^{S F 6}\left[\mu \mathrm{mol} \mathrm{kg}{ }^{-1}\right]$.

"supersaturated" samples to have $C_{a n t}$ values that are in equilibrium with contemporary atmospheric $\mathrm{pCO}_{2}$. For samples with pCFC-12>450 ppt, $C_{\text {ant }}^{F 12}$ is generally greater than $C_{a n t}^{S F 6}$, particularly for the time-invariant initial saturation case (panel a). The tendency for $C_{a n t}^{F 12}$ to be greater than $C_{a n t}^{S F 6}$ for high pCFC-12 samples is significantly reduced when the time-dependent initial saturation of CFC-12 is considered (panel b). For samples with pCFC-12 values between 100 and $450 \mathrm{ppt}$, there is generally good agreement between $C_{a n t}^{F 12}$ and $C_{a n t}^{S F 6}$, with the mean difference being $0.8 \pm 3.4$ and $0.4 \pm 3.4 \mu \mathrm{mol} \mathrm{kg}^{-1}$ for cases a) and b), respectively. The depth of the upper horizon where the two estimates agree closely (i.e., the pCFC- $12=450 \mathrm{ppt}$ isoline) is dependent on the local hydrography and corresponds to $C_{a n t}$ concentrations of about $40 \mu \mathrm{mol} \mathrm{kg}^{-1}$ in 2004. For older samples, i.e., samples with pCFC-12 < $100 \mathrm{ppt}, C_{a n t}^{S F 6}$ is generally higher than $C_{a n t}^{F 12}$. The reason for this is two-fold; measurement uncertainties associated with very low $\mathrm{pSF}_{6}$ values; as well as the short atmospheric history of $\mathrm{SF}_{6}$. The difference between the $C_{a n t}$ history and $\mathrm{SF}_{6}$ history is larger than that between $C_{a n t}$ and CFC-12, making $\mathrm{SF}_{6}$ a poor proxy for $C_{a n t}$ in older waters.

[32] Figures 6 and 7 shows sections of $\mathrm{pSF}_{6}, \mathrm{pCFC}-12$, $C_{\text {ant }}^{S F 6}$ and the difference between the two $C_{\text {ant }}$ estimates $\left(C_{a n t}^{F+12}-C_{a n t}^{S F G}\right)$, using the time-dependent initial saturation for CFC-12. As discussed above there is generally good agreement between the two estimates in the surface and below about $800 \mathrm{~m}$, but there are larger differences in a subsurface layer. For the western basin $C_{a n t}^{F 12}$ is up to $10 \mu \mathrm{mol} \mathrm{kg}{ }^{-1}$ higher than $C_{a n t}^{S F 6}$ in a subsurface layer between 200-500 m depth. However, for the Eastern Basin and in the northern part of section 2, the two $C_{\text {ant }}$ estimates are more consistent. The column inventory based on CFC-12 data for the upper $800 \mathrm{~m}$ during the M60/5 cruise is generally larger than the $\mathrm{SF}_{6}$ based inventory (average $\sim 1 \mathrm{~mol} \mathrm{~m}^{-2}$ ), although at individual stations this difference can be as large as $6 \mathrm{~mol} \mathrm{~m}{ }^{-2}$, i.e., up to roughly $6 \%$ of the total column inventory. The exception is the northernmost station (at $42^{\circ} \mathrm{N}$ ) where the $\mathrm{SF}_{6}$ based column inventory is larger by about $3 \mathrm{~mol} \mathrm{~m}^{-2}$ (Figure 7d).

\subsection{Uncertainty Arising From the $\Delta / \Gamma$ Ratio}

[33] We now explore the uncertainty associated with assuming a $\Delta / \Gamma$ ratio of 1 in the TTD calculations. We first compare the measured $\mathrm{pSF}_{6}$ versus $\mathrm{pCFC}-12$ from the $\mathrm{M} 60 / 5$ cruise in Figure 8. The dashed-dotted gray line is the $\mathrm{SF}_{6} / \mathrm{CFC}-12$ relation of the atmospheric history of these tracers, with selected time-markers indicated. All data points from the ocean would fall on this line in the extreme case of no mixing of waters with different ages (i.e., if $\Delta / \Gamma=0$ ). Clearly, the observations fall closer to a line that can be represented by assuming strong mixing within the ocean (i.e., $\Delta / \Gamma=1$ ), which is an indication that this ratio of mean age over the width of the TTD is realistic. The atmospheric histories of the two tracers are however not sufficiently different to allow exclusion of even stronger 
All data from M60/5

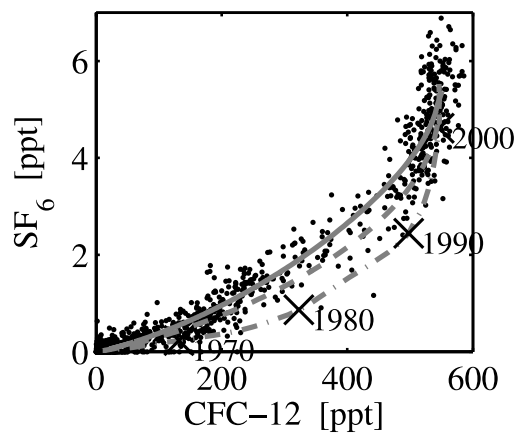

Figure 8. The dry air mole fraction of $\mathrm{SF}_{6}$ versus the dry air mole fraction of $\mathrm{CFC}-12$ for the $\mathrm{M} 60 / 5$ data set from year 2004 plotted as black dots. The gray dash-doted line is the atmospheric concentration of the two tracers over time, where a cross marks every 10 -year. This line is equal to the expected relation between the two tracers in the ocean with assumption of no mixing $(\Delta / \Gamma=0)$, the dashed line is the oceanic relation if $\Delta / \Gamma=0.5$ (i.e., moderate mixing) and the solid line is for the $\Delta / \Gamma=1$ (i.e., strong mixing) case. For this plot we have assumed timedependent saturation of CFC-12, and constant $86 \%$ saturation of $\mathrm{SF}_{6}$.

mixing, although a ratio of $\Delta / \Gamma=1$ was shown by Waugh et al. [2004] to be consistent with relations between several tracers.

[34] The dependence of the calculated TTDs to variation of the assumed $\Delta / \Gamma$ ratio is different for $\mathrm{SF}_{6}$ and CFC-12, and this translates into differences in the resulting $C_{a n t}$ estimates. Figure 9 shows the difference in $C_{a n t}$ estimates based on $\mathrm{SF}_{6}$ and CFC-12 for different assumed values of the $\Delta / \Gamma$ ratio. The gray lines in the panels indicate the averaged difference in the tracer age interval for which there is good agreement between $\mathrm{SF}_{6}$ and CFC-12 based $C_{\text {ant }}$ estimates. The difference in $C_{a n t}$ is generally relatively small for the three cases, indicating that the sensitivity to the $\Delta / \Gamma$ ratio for the $C_{a n t}$ calculation is relatively small. The good fit for estimates based on $\Delta / \Gamma$ ratio of 1 is another indication that this indeed might be a reasonable approximation of ocean mixing.

\subsection{Comparison to eMLR Based Estimates}

[35] The so-called "extended Multiple Linear Regression" (eMLR) method for $C_{a n t}$ estimates of Friis et al. [2005] uses multiple linear regressions of dissolved inorganic carbon on repeated measurements of inorganic carbon and related hydrochemical properties. The coefficients of the two regressions are subtracted resulting in a new multivariate equation that predicts the differences in DIC between the two data sets that are not correlated with temporal changes of the underlying hydrochemical parameters. The interpretation is that natural variability of DIC between the two dats sets are compensated via the regression on hydrochemical parameters that are known to influence DIC (e.g., oxygen and temperature changes) whereas the remaining "unexplained" differences relate to changes in $C_{a n t}\left(\Delta C_{a n t}\right)$ between the two surveys. The total $C_{a n t}$ can then be estimated from $\Delta C_{a n t}$ via an extrapolation method presented by Tanhua et al. [2007]. More information on the approach as well as a comparison between the TTD method (CFC-12) and the eMLR method using the same data set but focusing more on deeper layers are presented by Tanhua et al. [2007]. Importantly, the resulting estimates from the eMLR method are completely independent of transient tracer data.

[36] This comparison reveals larger differences of $C_{a n t}$ estimates between the two methods (eMLR versus TTD) than between the TTD method using the two tracers. Figure 10a show the difference between the eMLR and TTD derived estimates of $C_{a n t}$, and Panels B and C show box and whisker plots for all samples from M60/5. It is notable that there are a number of shallow samples for which there are large $\left(\sim 20\right.$ umol $\left.\mathrm{kg}^{-1}\right)$ discrepancies between the TTD and eMLR based methods, and that the spread of $C_{a n t}$ estimates for the shallower samples is smaller for the TTD method (panel B), than for the eMLR method (panel C). This is most likely due to seasonal variations in carbon related properties such as oxygen, nutrients and DIC. These variations can affect estimates of $C_{a n t}$ from the eMLR method, but are not directly effecting the TTD method. The spread and the absolute values of the two $C_{a n t}$ estimates are quite similar for deeper samples. It seems that the tracerbased TTD method may be preferable to the eMLR method
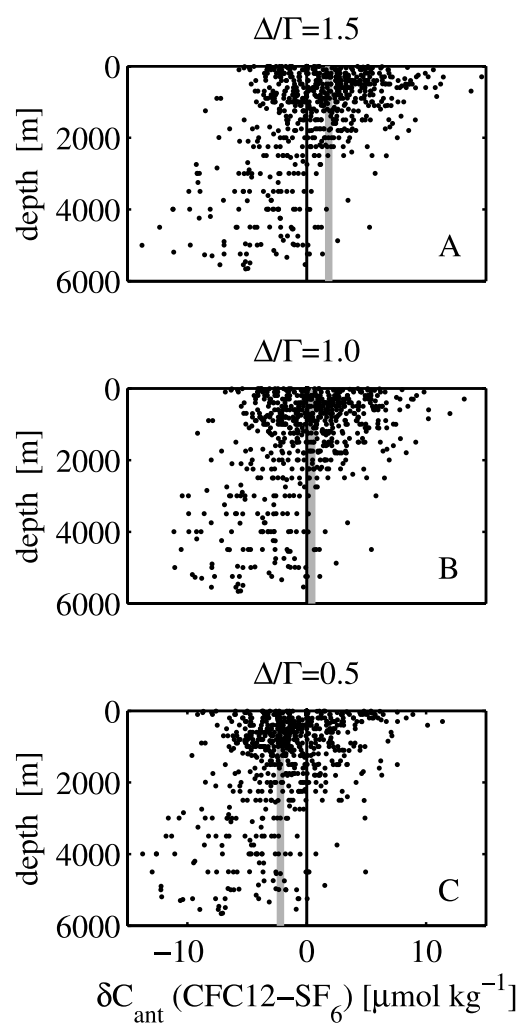

Figure 9. Difference in anthropogenic carbon content based either on $\mathrm{SF}_{6}$ or CFC-12 measurements (calculated using the TTD method) plotted versus depth for different assumptions on mixing. The data are from the M60/5 cruise in 2004. The gray lines mark the mean difference in the CFC-12 concentration range of 100 to $450 \mathrm{ppt}$ (see Figure 5). Panel A assumes a $\Delta / \Gamma$ ratio of 1.5 ; panel B 1.0 ; and panel $\mathrm{C} 0.5$. 

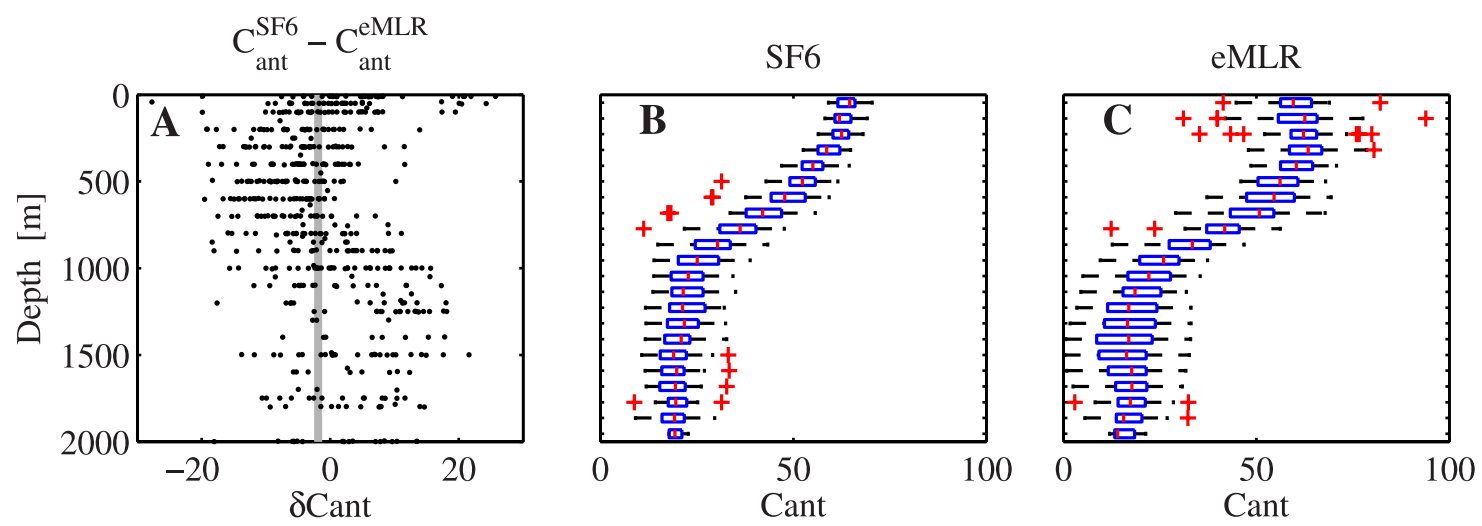

Figure 10. Comparison of $C_{a n t}$ estimates using either the TTD method applied on $\mathrm{SF}_{6}$ data or the eMLR method. Panel A: The difference between $C_{\text {ant }}^{S F 6}$ and $C_{\text {ant }}^{e M L R}\left(\mu \mathrm{mol} \mathrm{kg}{ }^{-1}\right)$ versus depth for all the data from the M60/5 cruise above $2000 \mathrm{~m}$. Note the larger scale for the $x$ axis compared to Figures 5 and 9. Panels $\mathrm{B}$ and $\mathrm{C}$ are box and whisker plots of $C_{a n t}^{S F 6}$ and $C_{a n t}^{e M L R}$, respectively, where the $C_{a n t}$ concentrations (in $\mu \mathrm{mol} \mathrm{kg}{ }^{-1}$ ) are interpolated to standard depths (10 50 100:100:2000 m depth). Each box defines the lower and upper quartile of the data, the whiskers shows the extent of the rest of the data, with outliers marked with red crosses.

in the upper part of the ocean that is strongly affected by seasonal variations.

\section{Conclusion}

[37] $\mathrm{SF}_{6}$ and $\mathrm{CFC}-12$ based estimates of $C_{\text {ant }}$ using the TTD method have different sensitivities to uncertainties in the measurement of the tracer and to assumptions regarding the initial saturation of the tracer at the time of water mass formation. We have shown that the post-1980s reduction of the atmospheric growth rate of CFC-12 increases the uncertainty of $C_{a n t}$ estimations based on CFC-12 for samples ventilated recently, although the effect on older waters is small. For data collected before the end of the 1990s (e.g., WOCE data and the GLODAP synthesis), the CFC-12 growth rate was still sufficiently high to allow accurate determination of TTDs, and thus $C_{\text {ant }}$. However, for more recent data, i.e., for $\mathrm{pCFC}-12>450 \mathrm{ppt}$, the uncertainty associated with the TTD estimation is rapidly increasing.

[38] We have demonstrated an empirical relationship between atmospheric growth rate of CFC-12 and its mean surface saturation. Applying this time-dependency in the TTD calculation improves the agreement between $\mathrm{SF}_{6}$ and CFC-12 based estimates of $C_{\text {ant }}$.

[39] Data from a cruise in the midlatitude North Atlantic show generally positive values of $C_{a n t}^{F 12}-C_{a n t}^{S F 6}$ for recently ventilated samples, i.e., samples with higher $C_{\text {ant }}$ concentrations. This is most likely due to errors in the assumption of initial saturation, which will affect $C_{a n t}^{F 12}$ estimates considerable more than $C_{a n t}^{S F 6}$ estimates, Figure 3. As $C_{\text {ant }}^{S F 6}$ is less sensitive to uncertainties in the assumed initial saturation, this estimate is likely a better basis for $C_{a n t}$ estimation in the upper water column. For older samples, i.e., with pCFC-12 $<100 \mathrm{ppt}, C_{a n t}^{S F 6}$ is systematically higher than $C_{a n t}^{F 12}$. This likely relates to difficulties associated with making accurate measurements of very low $\mathrm{SF}_{6}$ concentrations in the deep ocean, as well as a larger difference between the $C_{a n t}$ and $\mathrm{SF}_{6}$ histories than between the $C_{a n t}$ and CFC-12 histories.
[40] Since the CFC-12 can to date be determined with higher precision and accuracy, it tends to produce more precise $C_{\text {ant }}$ estimates for samples with pCFC $<450 \mathrm{ppt}$. As the atmospheric concentration of $\mathrm{CFC}-12$ is now decreasing, and is predicted to continue to do so, we have demonstrated that $\mathrm{CFC}$ measurements benefit from complementary $\mathrm{SF}_{6}$ measurements, and that the $\mathrm{SF}_{6}$ data provide a better basis for tracer based $C_{a n t}$ estimations in recently ventilated waters.

[41] Acknowledgments. The study was supported by the Deutsche Forschungsgemeinschaft (DFG) through SFB 460 and grants for the M60/5 cruise. T.T. was supported by a Marie Curie Fellowship of the European Community program "Improving Human Research Potential and the Socioeconomic Knowledge Base" under contract number HPMF-CT-200201697. Darryn Waugh. was supported by NOAA grant NA04AR4310118 and NSF grant OCE-0623423. We acknowledge the cooperation of the Captain, officers and crew of RV Meteor and the excellent work of the $\mathrm{SF}_{6}$ and $\mathrm{CFC}$-measurement teams (Martina Schütt, Elke Freese and Tim Fischer). Support form the EU supported IP CARBOOCEAN is acknowledged.

\section{References}

Azetsu-Scott, K., E. P. Jones, I. Yashayaev, and R. M. Gershey (2003), Time series study of CFC concentrations in the Labrador Sea during deep and shallow convection regimes $(1991-2000)$, J. Geophys. Res., 108(C11), 3354, doi:10.1029/2002JC001317.

Azetsu-Scott, K., E. P. Jones, and R. M. Gershey (2005), Distribution and ventilation of water masses in the Labrador Sea inferred from CFCs and carbon tetrachloride, Mar. Chem., 94, 55-66, doi:10.1016/j.marchem. 2004.07.015.

Brewer, P. G. (1978), Direct observation of the oceanic CO2 increase, Geophys. Res. Lett., 5(12), 991-1000.

Brewer, P., A. L. Bradshaw, and R. T. Williams (1986), Measurements of total carbon dioxide and alkalinity in the North Atlantic Ocean in 1981, in The Changing Carbon Cycle. A Global Analysis, edited by J. R. Trabalka and D. E. Reichele, Springer-Verlag, New York.

Bullister, J. L., and R. F. Weiss (1988), Determination of $\mathrm{CCl}_{3} \mathrm{~F}$ and $\mathrm{CCl}_{2} \mathrm{~F}_{2}$ in seawater and air, Deep Sea Res., 35, 839-853.

Bullister, J. L., D. P. Wisegarver, and F. A. Menzia (2002), The solubility of sulfur hexafluoride in water and seawater, DeepSea Res., Part I, 49, $175-187$.

Bullister, J. L., D. P. Wisegarver, and R. E. Sonnerup (2006), Sulfur hexafluoride as a transient tracer in the North Pacific Ocean, Geophys. Res. Lett., 33, L18603, doi:10.1029/2006GL026514.

Chen, C.-T., and F. Millero (1979), Gradual increase of oceanic CO2, Nature, 277, 1093 
DeGrandpre, M. D., A. Kortzinger, U. Send, D. W. R. Wallace, and R. G. J. Bellerby (2006), Uptake and sequestration of atmospheric CO2 in the Labrador Sea deep convection region, Geophys. Res. Lett., 33, L21503, doi:10.1029/2006GL026881.

Friis, K., A. Körtzinger, J. Pätsch, and D. W. R. Wallace (2005), On the temporal increase of anthropogenic $\mathrm{CO}_{2}$ in the subpolar North Atlantic, DeepSea Res., Part I, 52, 681-698, doi:10.1016/j.dsr.2004.11.017.

Gruber, N., J. L. Sarmiento, and T. F. Stocker (1996), An improved method for detecting anthropogenic $\mathrm{CO} 2$ in the oceans, Global Biogeochem. Cycles, 10(4), 809-837.

Haine, T. W. N., and K. J. Richards (1995), The influence of the seasonal mixed layer on oceanic uptake of CFCs, J. Geophys. Res., 100(C6), $10,727-10,744$.

Hall, T. M., T. W. N. Haine, and D. W. Waugh (2002), Inferring the concentration of anthropogenic carbon in the ocean from tracers, Global Biogeochem. Cycles, 16(4), 1131, doi:10.1029/2001GB001835.

Hall, T. M., D. W. Waugh, T. W. N. Haine, P. E. Robbins, and S. Khatiwala (2004), Estimates of anthropogenic carbon in the Indian Ocean with allowance for mixing and time-varying air-sea $\mathrm{CO} 2$ disequilibrium, Global Biogeochem. Cycles, 18, GB1031, doi:10.1029/2003GB002120.

Key, R. M., A. Kozyr, C. L. Sabine, K. Lee, R. Wanninkhof, J. L. Bullister, R. A. Feely, F. J. Millero, C. Mordy, and T. H. Peng (2004), A global ocean carbon climatology: Results from Global Data Analysis Project (GLODAP), Global Biogeochem. Cycles, 18, GB4031, doi:10.1029/ $2004 \mathrm{~GB} 002247$.

Law, C. S., and A. J. Watson (2001), Determination of Persian Gulf water transport and oxygen utilisation rates using $\mathrm{SF}_{6}$ as a novel transient tracer Geophys. Res. Lett., 28(5), 815-818.

Lo Monaco, C., C. Goyet, N. Metzl, A. Poisson, and F. Tourtier (2005), Distribution and inventory of anthropogenic $\mathrm{CO} 2$ in the southern ocean: Comparison of three data-based methods, J. Geophys. Res., 110, C09502, doi:10.1029/2004JC002571.

Maiss, M., and C. A. M. Brenninkmeijer (1998), Atmospheric SF6: Trends, sources, and prospects, Environ. Sci. Technol., 32, 3077-3086.

Matsumoto, K., and N. Gruber (2005), How accurate is the estimation of anthropogenic carbon in the ocean? An evaluation of the DeltaCstar method, Global Biogeochem. Cycles, 19, GB3014, doi:10.1029/ 2004GB002397.

Mecking, S., M. J. Warner, C. E. Greene, S. L. Hautala, and R. E. Sonnerup (2004), Influence of mixing on CFC uptake and CFC ages in the North Pacific thermocline, J. Geophys. Res., 109, CO7014, doi:10.1029/ 2003JC001988

Prinn, R. G., et al. (2000), A history of chemically and radiatively important gases in air deduced from ALE/GAGE/AGAGE, J. Geophys. Res., 105 17,751-17,792, doi:10.1029/2006GB002695.

Schmitt, R. W., J. R. Ledwell, E. T. Montgomery, K. L. Polzin, and J. M. Toole (2005), Enhanced diapycnal mixing by salt fingers in the thermocline of the Tropical Atlantic, Science, 308, 685-688.

Tanhua, T., K. A. Olsson, and E. Fogelqvist (2004), A first study of $\mathrm{SF}_{6}$ as a transient tracer in the southern ocean, Deep Sea Res., Part II, 51, 2683 2699.

Tanhua, T., K. Bulsiewicz, and M. Rhein (2005), Spreading of overflow water from the Greenland to the Labrador Sea, Geophys. Res. Lett., 32 , L10615, doi:10.1029/2005GL022700.

Tanhua, T., A. Biastoch, A. Körtzinger, H. Lüger, C. Böning, and D. W. R. Wallace (2006), Changes of anthropogenic $\mathrm{CO}_{2}$ and CFCs in the North Atlantic between 1981 and 2004, Global Biogeochem. Cycle, 20 GB4017.
Tanhua, T., A. Körtzinger, K. Friis, D. W. Waugh, and D. W. R. Wallace (2007), An estimate of anthropogenic CO2 inventory from decadal changes in ocean carbon content, PNAS, 104(9), 3037-3042.

Thomas, H., and M. H. England (2002), Different oceanic features of anthropogenic $\mathrm{CO}_{2}$ and CFCs, Naturwissenschaften, 89, 399-403.

Thomas, H., and V. Ittekkot (2001), Determination of anthropogenic $\mathrm{CO}_{2}$ in the North Atlantic Ocean using water mass ages and $\mathrm{CO}_{2}$ equilibrium chemistry, J. Mar. Syst., 27, 325-336.

Thomas, H., M. England, and V. Ittekkot (2001), An off-line 3D model of anthropogenic CO2 uptake by the oceans, Geophys. Res. Lett., 28(3), $547-550$.

Touratier, F., and C. Goyet (2004), Applying the new TrOCA approach to assess the distribution of anthropogenic $\mathrm{CO} 2$ in the Atlantic Ocean, J. Mar. Syst., 46, 181-197.

Vázquez-Rodríguez, M., F. Touratier, C. Lo Monaco, D. W. Waugh, X. A Padin, R. G. J. Bellerby, C. Goyet, N. Metzl, A. F. Ríos, and F. F. Pérez (2008), Anthropogenic carbon distributions in the Atlantic Ocean: Databased estimates from the Arctic to the Antarctic, Biogeosciences Discuss., $5,1421-1443$.

Vollmer, M. K., and R. F. Weiss (2002), Simultaneous determination of sulfur hexafluoride and three chlorofluorocarbons in water and air, Mar. Chem., 78(2-3), 137-148.

Walker, S. J., R. F. Weiss, and P. K. Salameh (2000), Reconstructed histories of the annual mean atmospheric mole fractions for the halocarbons CFC-11, CFC-12, CFC-113 and carbon tetrachloride, J. Geophys. Res., 105(C6), 14,285-14,296.

Wallace, D. W. R. (2001), Ocean measurements and models of carbon sources and sinks, global biogeochemical cycles, Global Biogeochem. Cycles, 15(1), 3-11.

Wallace, D. W. R., and J. R. N. Lazier (1988), Anthropogenic chlorofluoromethanes in newly formed Labrador Sea water, Nature, 332, 61-63.

Warner, M. J., and R. F. Weiss (1985), Solubilities of chlorofluorocarbons 11 and 12 in water and sea water, Deep Sea Res., 32, 1485-1497.

Watanabe, Y., A. Shimamoto, and T. Ono (2003), Comparison of timedependent tracer ages in the western North Pacific: Oceanic background levels of SF6, CFC-11. CFC-12 and CFC-113, J. Oceanogr., 59, 719729

Watson, A. J., and J. R. Ledwell (2000), Oceanic tracer release experiments using sulphur hexafluoride, J. Geophys. Res., 105(C6), 14,325-14,337.

Waugh, D. W., T. M. Hall, and T. W. N. Haine (2003), Relationship among tracer ages, J. Geophys. Res., 108(C5), 3138, doi:10.1029/ 2002JC001325.

Waugh, D. W., T. M. Hall, and T. W. N. Haine (2004), Transport times and anthropogenic carbon in the subpolar North Atlantic Ocean, Deep Sea Res., Part I, 51, 1471-1491, doi:10.1016/j.dsr.2004.06.011.

Waugh, D. W., T. M. Hall, B. I. McNeil, R. Key, and R. J. Matear (2006), Anthropogenic $\mathrm{CO} 2$ in the Oceans estimated using transit-time distributions, Tellus, Ser. A and Ser. B, 58B, 376-389, doi:10.1111/j.1600-0889. 2006.00222.x.

Zhao, J., J. Y. Sheng, R. J. Greatbatch, K. Azetsu-Scott, and E. P. Jones (2006), Simulation of CFCs in the North Atlantic Ocean using an adiabatically corrected ocean circulation model, J. Geophys. Res., 111 C06027, doi:10.1029/2004JC002814.

T. Tanhua and D. W. R. Wallace, Leibniz-Institut für Meereswissenschaften, Marine Biogeochemie, Düsternbrooker Weg 20, D-24105 Kiel, Germany. (ttanhua@ifm-geomar.de)

D. W. Waugh, Department of Earth and Planetary Sciences, Johns Hopkins University, 3400 North Charles Street, Baltimore, MD 21218, USA. 